\title{
Mesenteric occlusive disease of the inferior mesenteric artery is associated with anastomotic leak after left-sided colon and rectal cancer surgery: a retrospective cohort study
}

\author{
Melissa N. N. Arron ${ }^{1}$ - Richard P. G. ten Broek ${ }^{1}$ - Carleen M. E. M. Adriaansens ${ }^{1}$ - Stijn Bluiminck ${ }^{1}$ - Bob J. van Wely ${ }^{2}$. \\ Floris T. J. Ferenschild ${ }^{3}$ · Henk F. M. Smits ${ }^{4}$ Harry van Goor ${ }^{1}$. Johannes H. W. de Wilt ${ }^{1} \cdot$ André S. van Petersen $^{2}$
}

Accepted: 18 December 2021 / Published online: 7 January 2022

(c) The Author(s) 2022

\begin{abstract}
Purpose Anastomotic leak (AL) is a serious complication following colorectal surgery. Atherosclerosis causes inadequate anastomotic perfusion and is suggested to be a risk factor for AL. The aim of this study was to investigate the association of mesenteric occlusive disease on preoperative computed tomography (CT) scan with AL after left-sided colon or rectal cancer surgery.

Methods This was a retrospective, multicenter cohort study including 1273 patients that underwent left-sided or rectal cancer resection between 2009 and 2018 from three hospitals in the Netherlands. AL patients were 1:1 matched with non-leak patients and preoperative contrast-enhanced CT-scans were retrospectively analyzed for mesenteric atherosclerotic lesions. The main outcome measure was the presence of mesenteric occlusive disease on the preoperative CT-scan.

Results Anastomotic leak developed in $6 \%$ of 1273 patients $(N=76)$. Low anterior resection and stage I-III disease were statistically significant associated with $\operatorname{AL}(p=0.01, p=0.04)$. No other statistically significant differences in patient characteristics between AL and non-leak patients were found. A clinically significant stenosis $(\geq 70-100 \%)$ of the inferior mesenteric artery was statistically significant more frequent present in AL patients, compared to non-leak patients $(p<0.01)$. No statistically significant differences in the presence of mesenteric occlusive disease of the celiac artery and superior mesenteric artery between AL patients and non-leak patients were found.

Conclusion Mesenteric occlusive disease of the IMA on preoperative CT-scan is associated with AL after left-sided colon or rectal resection for cancer. Preoperative identification of high-risk patients with a preoperative CT-scan of the mesenteric vasculature might be useful to reduce the risk of AL.
\end{abstract}

Keywords Mesenteric occlusive disease $\cdot$ Colorectal cancer $\cdot$ Colorectal surgery $\cdot$ Anastomotic leakage

Melissa N. N. Arron

Melissa.Arron@ radboudumc.nl

$\triangle$ Richard P. G. ten Broek

richard.tenbroek@radboudumc.nl

1 Department of Surgery, Radboud Institute for Health Sciences, Radboud University Medical Center, Geert Grooteplein Zuid 10 (internal post 618), 6525 GA Nijmegen, The Netherlands

2 Department of Surgery, Bernhoven Hospital, Uden, The Netherlands

3 Department of Surgery, Maashospital Pantein, Boxmeer, The Netherlands

4 Department of Radiology, Bernhoven Hospital, Uden, The Netherlands

\section{Introduction}

Anastomotic leakage (AL) is a severe complication of colorectal cancer surgery. It is associated with severe morbidity and high mortality rates [1-3]. Despite extensive research, incidence of AL remains high, with distal anastomoses being associated with the highest leak rates [4]. Many risk factors for AL have been identified, including smoking and male sex $[2,5,6]$. Inadequate anastomotic vascular perfusion has also been suggested to be an important contributor to the development of AL [7, 8].

Perfusion is essential in wound healing in general, and inadequate anastomotic perfusion might therefore threaten healing of anastomotic tissue [7, 9]. Atherosclerotic calcification is one of the main causes of inadequate perfusion 
and is also suggested to be a potential risk factor for $\mathrm{AL}$ $[10,11]$.

Several recent studies demonstrated that atherosclerotic calcification of the aorta-iliac tract on preoperative CT-scan is associated with an increased risk of AL [12-14]. Although calcification in large arteries might mirror the anastomotic perfusion, the blood supply of the colorectal region is primary provided by the inferior mesenteric artery (IMA). In addition, adequate anastomotic perfusion also depends on the presence and patency of the collateral circulation (e.g. Riolan) as well as on the compensatory function of the superior mesenteric artery (SMA) and celiac artery (CA) [15]. Until now, evidence on the role of mesenteric occlusive disease in AL is limited and only one small study has been performed yet [16].

Preoperative identification of patients at risk of inadequate anastomotic perfusion with a preoperative CT-scan of the mesenteric vasculature is low-cost and minimally invasive. It may provide opportunities to modify these vascular risk factors and to take preventive measures (e.g. construction of a diverting stoma) to reduce the risk for AL. We hypothesize that mesenteric occlusive disease of the IMA, SMA, and CA, diagnosed with preoperative abdominal CT-scan is associated with AL. Therefore, in the present study we investigated the association of mesenteric occlusive disease on preoperative abdominal CT-scan with AL after left-sided colon or rectal cancer surgery in a population-based cohort.

\section{Materials and methods}

All patients $(N=1273)$ who underwent elective or emergency colorectal resection with construction of an anastomosis for primary left-sided colon, sigmoid or rectal cancer at three Dutch hospitals, Radboud University Medical Center, Bernhoven Hospital and Maas hospital Pantein, between January 2009 and December 2018 were retrospectively analyzed. Data on baseline and surgeryrelated parameters was retrieved from local extractions of the Dutch ColoRectal Audit (DCRA), a populationbased audit. The following baseline and surgery-related parameters were retrieved: age, body mass index (BMI), ASA score, comorbidities, pathological TNM stage, surgical procedure, (deviating) stoma creation, AL, surgical treatment for AL, stoma construction at reoperation for AL, intensive care unit (ICU) admission, 90-day hospital readmission, and length of hospital stay. In this study, the low-tie technique was used in rectal cancer surgery. This is according to previous studies demonstrating that the lowtie technique is associated with a higher blood flow ratio compared to high-tie, which may benefit anastomotic perfusion [8]. More detailed information on AL was collected from the electronic patient records of all AL patients. The following data items were collected: smoking status, date of reintervention for $\mathrm{AL}$, conservative or radiological treatment for $\mathrm{AL}$, and stoma reversal during the postoperative follow-up. Data regarding AL from the electronic patient record was only collected after written informed consent of the patient. Eight AL patients declined to give consent or did not respond, and their data was not included in the analysis.

To assess the presence of mesenteric occlusive disease, preoperative contrast-enhanced CT-scans were retrospectively reviewed for atherosclerotic lesions by a vascular surgeon (A. P.) and radiologist (H.S.). These preoperative contrast-enhanced CT-scans with a 5-mm slice thickness were performed for oncological staging with no specific attention for the presence of atherosclerotic lesions. Of $76 \mathrm{AL}$ patients, CT-scans of 52 patients were available for assessment and $24 \mathrm{CT}$-scans of AL were not available due to insufficient quality $(N=16)$ or the patient did not give consent for access to their electronic patient record $(N=8)$ (see Flowchart; Fig. 1). We performed case-control matching to create a cohort including AL and non-leak patients with equal risks on the presence of mesenteric occlusive disease on the CT-scan. Patients with AL of whom the CT-scan was available $(N=52)$, were matched with non-leak patients $(N=52)$ selected from the same cohort to create a representative sample of the total population. Non-leak patients were chosen using 1:1 case-control matching with AL patients based on age, $\mathrm{BMI}$, and cardiovascular comorbidity; all risk factors for mesenteric occlusive disease. The patency of the IMA, SMA, and CA was reviewed during the inspiration phase of the CT scan. The degree of stenosis was classified into four groups: no atherosclerotic lesions, stenosis $<50 \%$, stenosis $\geq 50 \%-70 \%$, and clinically significant stenosis $\geq 70 \%-100 \%$. Figure 2 shows CT-images of these four groups. The presence of a collateral circulation between the IMA and SMA was graded according to the following classification: 0 - not visible/absent, 1 - present, but poor visibility, 2 - present and good visibility. The reviewers were blinded for clinical information to prevent bias. Discrepancies between the reviewers on the scoring were solved by re-examination of the CT-scan until consensus was reached. The individual scores of both reviewers and the final score (after consensus was reached) are depicted in suppl. Table 1.

The primary outcome of this study was the presence of mesenteric occlusive disease on the preoperative CT-scan. Secondary outcome was colorectal AL, defined as clinically relevant AL that requires reintervention within 90 days after surgery.

The local medical ethical committee reviewed and approved the study protocol (registration number 2019-5269). 
Fig. 1 Flowchart

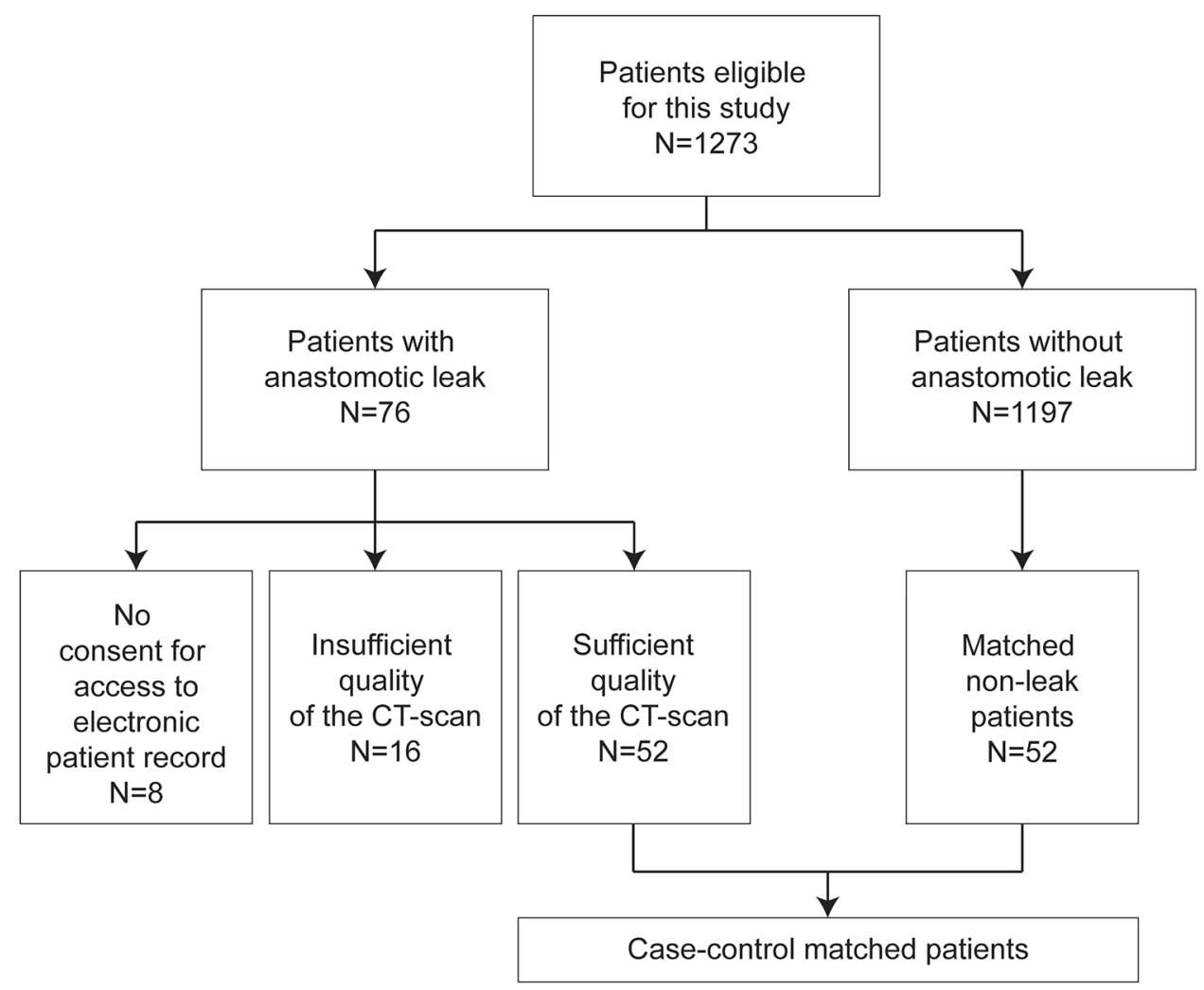

\section{Statistical analysis}

The data were analyzed using the SPSS statistical software version 25.0. Differences in baseline characteristics, postoperative outcomes and the presence of stenoses of the mesenteric arteries (no, $<50 \%, \geq 50-70 \%, \geq 70-100 \%$ ) between $\mathrm{AL}$ patients and non-leak patients were presented as frequencies and percentages and analyzed using Fisher's exact test (observed count $<10$ ) or chi $^{2}$-test for binominal data. For skewed continuous data (e.g., length of hospital stay) the Mann-Whitney $U$ test was used, and data was presented as median with interquartile range (IQR). All reported $p$-values were two-sided, a $p$-level of $<0.05$ was used as the level of significance.

\section{Results}

\section{Baseline characteristics}

Between January 2009 and December 2018, a total of 1273 patients underwent colorectal resection with primary anastomosis for colorectal cancer in this cohort. The median age of patients included in this study was 67 years (IQR 61-74). In 905 patients $(71 \%)$ a left-sided colectomy or sigmoid resection was performed and 367 patients (29\%) underwent low anterior resection (LAR). Two hundred patients (16\%) received a deviating stoma at resection of the tumor. There were 22 AL (29\%) patients with a history of smoking or who were currently smoking. Univariable analysis revealed LAR and stage I-III disease to be risk factors for AL $(p=0.01$, $p=0.04)$. No other differences in baseline characteristics were found between AL patients and non-leak patients at univariate analysis as depicted in Table 1 . In the case-control matched patient cohort, there were also no baseline differences between AL patients and matched non-leak patients, except for LAR and male sex being associated with an increased risk of AL $(p=0.04)$. The median age was 65 years (IQR 57-70), without statistically significant differences between groups. A total of 69 patients underwent left colon resection (66\%), 35 patients (34\%) underwent rectal resection, and 17 patients $(15 \%)$ received a deviating stoma at primary resection. Twenty-four patients were diagnosed with any cardiovascular comorbidity (23\%), with equal distribution over the AL and matched nonleak group. The results are depicted in Table 1.

\section{Postoperative outcomes}

AL developed in 76 out of 1273 patients (6\%). Of the 76 AL patients, 33 patients (43\%) underwent rectal resection, and 43 patients $(57 \%)$ underwent colon resection. Median days until reintervention for AL were five days (IQR 3-11). AL was treated with a surgical reintervention in 62 patients 
Fig. 2 Abdominal CT-images of patients with mesenteric occlusive disease
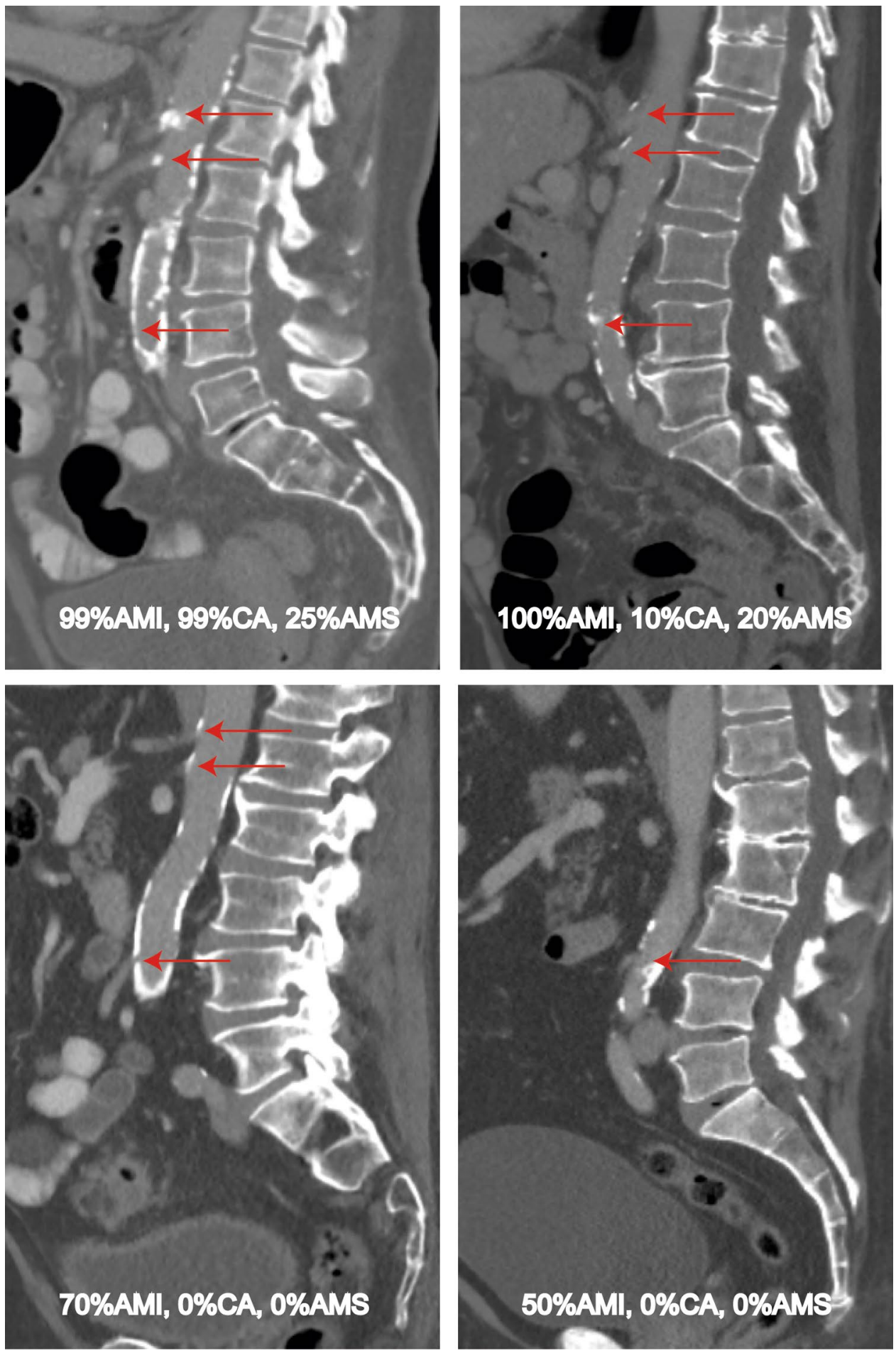

(82\%). Twelve patients (16\%) were treated with radiological intervention and one patient $(1 \%)$ received conservative treatment (i.e. intravenous antibiotics). Of patients treated with surgical reintervention, 55 patients $(89 \%)$ received a stoma; 33 patients $(60 \%)$ were treated with an end colostomy and 22 patients $(40 \%)$ with a deviating stoma. Most of the AL patients who received a stoma either at primary resection or at reintervention still had a stoma at 1 year postoperative $(64 \%, N=35)$. Four AL patients died within the first year after surgery (5\%). The patients with AL had statistically significant worse postoperative outcomes compared to nonleak patients: a higher ICU admission rate (47\% versus $12 \%$, $p=0.00)$ and a higher 90 -day readmission rate (36\% versus $8 \%, p=0.00$ ). Median length of hospital stay for AL patients 
Table 1 Baseline patient-, tumor-, and treatment characteristics

\begin{tabular}{|c|c|c|c|c|c|c|c|}
\hline & \multirow{2}{*}{$\begin{array}{l}\text { Total } \\
\text { population } \\
N=1273\end{array}$} & \multicolumn{3}{|c|}{ Unmatched patients } & \multicolumn{3}{|c|}{ Case-control matched patients } \\
\hline & & $\begin{array}{l}\text { Anastomotic } \\
\text { leakage } \\
N=76\end{array}$ & $\begin{array}{l}\text { No anastomotic } \\
\text { leakage }(N=1197)\end{array}$ & $\begin{array}{l}p \text {-value } \\
A L \text { vs. } \\
\text { no } A L\end{array}$ & $\begin{array}{l}\text { Anastomotic } \\
\text { leakage } N=52\end{array}$ & $\begin{array}{l}\text { Matched "no } \\
\text { anastomotic leak" } \\
\text { cohort } N=52\end{array}$ & $\begin{array}{l}p \text {-value } A L \text { vs. } \\
\text { matched no } A L\end{array}$ \\
\hline & $N(\%)$ & $N(\%)$ & & & $N(\%)$ & & \\
\hline \multicolumn{8}{|l|}{ Age } \\
\hline$<70$ & 758 & $53(69.7)$ & $705(58.9)$ & 0.07 & $40(76.9)$ & $40(76.9)$ & 1.00 \\
\hline$\geq 70$ & 514 & $23(30.3)$ & $491(41.1)$ & & $12(23.1)$ & $12(23.1)$ & \\
\hline \multicolumn{8}{|l|}{ BMI } \\
\hline$<18.5$ & 16 & $0(0.0)$ & $16(1.3)$ & 0.46 & $0(0.0)$ & $0(0.0)$ & 0.91 \\
\hline $18.5-25.0$ & 431 & $30(39.5)$ & $401(33.5)$ & & $21(40.4)$ & $19(36.5)$ & \\
\hline $25.1-29.9$ & 550 & $34(44.7)$ & $516(43.1)$ & & $24(46.2)$ & $26(50.0)$ & \\
\hline $30-34.9$ & 222 & $10(13.2)$ & $212(17.7)$ & & $6(11.5)$ & $6(11.5)$ & \\
\hline Missing & 55 & $2(2.6)$ & $53(4.3)$ & & $1(1.9)$ & $1(1.9)$ & \\
\hline \multicolumn{8}{|l|}{ ASA } \\
\hline I & 275 & $16(21.1)$ & $259(21.7)$ & 0.48 & $10(17.3)$ & $19(36.5)$ & 0.06 \\
\hline II & 766 & $43(56.6)$ & $723(60.5)$ & & $30(57.7)$ & $28(53.8)$ & \\
\hline $\mathrm{III}+$ & 218 & $17(22.4)$ & $201(16.8)$ & & $12(23.1)$ & $5(9.6)$ & \\
\hline Missing & 13 & $0(0.0)$ & $13(1.1)$ & & - & - & \\
\hline \multicolumn{8}{|l|}{ Comorbidity } \\
\hline Myocard infarction & 128 & $11(14.5)$ & $117(9.8)$ & 0.23 & $5(9.6)$ & $5(9.6)$ & 1.00 \\
\hline $\begin{array}{l}\text { Peripheral arterial } \\
\text { failure/AAA }\end{array}$ & 44 & $2(2.6)$ & $42(3.5)$ & 1.00 & $1(1.9)$ & $1(1.9)$ & 1.00 \\
\hline $\begin{array}{l}\text { Cerebrovascular } \\
\text { disease (CVA, } \\
\text { TIA) }\end{array}$ & 89 & $6(7.9)$ & $83(6.9)$ & 0.65 & $2(3.8)$ & $5(9.6)$ & 0.44 \\
\hline Diabetes mellitus & 166 & $10(13.2)$ & $156(13.0)$ & 1.00 & $6(11.5)$ & $5(9.6)$ & 1.00 \\
\hline \multicolumn{8}{|c|}{ Pathological tumor stage } \\
\hline (y)pT0-pT2 & 554 & $32(42.1)$ & $522(43.6)$ & 0.67 & $23(44.2)$ & $13(25.0)$ & 0.08 \\
\hline (y)pT3-pT4 & 688 & $44(57.9)$ & $644(53.8)$ & & $29(55.8)$ & $38(73.1)$ & \\
\hline (y)pTX/unknown & 30 & $0(0.0)$ & $30(2.6)$ & & - & $1(1.9)$ & \\
\hline \multicolumn{8}{|l|}{ Pathological node stage } \\
\hline pNO & 704 & $40(52.6)$ & $664(55.5)$ & 0.30 & $28(53.8)$ & $31(59.6)$ & 0.83 \\
\hline $\mathrm{pN} 1$ & 270 & $21(27.6)$ & $249(20.8)$ & & $12(23.1)$ & $13(25.0)$ & \\
\hline $\mathrm{pN} 2$ & 142 & $6(7.9)$ & $136(11.4)$ & & $5(9.6)$ & $8(15.4)$ & \\
\hline pNx/unknown & 156 & $9(11.8)$ & $147(12.3)$ & & $7(13.5)$ & - & \\
\hline \multicolumn{8}{|l|}{ Cancer stage } \\
\hline Stages I-III & 1021 & $67(88.2)$ & $954(79.8)$ & 0.04 & $45(86.5)$ & $45(86.5)$ & 0.36 \\
\hline Stage IV & 94 & $1(1.3)$ & $93(7.8)$ & & $1(1.9)$ & $4(7.7)$ & \\
\hline Unknown & 164 & $8(10.5)$ & $156(12.5)$ & & $6(11.5)$ & $3(5.8)$ & \\
\hline \multicolumn{8}{|l|}{ Surgical procedure } \\
\hline $\begin{array}{l}\text { Left hemicolec- } \\
\text { tomy/sigmoid } \\
\text { resection }\end{array}$ & 905 & $43(56.6)$ & $862(72.1)$ & 0.01 & $29(55.8)$ & $40(76.9)$ & 0.04 \\
\hline $\begin{array}{l}\text { (Low) anterior } \\
\text { resection }\end{array}$ & 367 & $33(43.4)$ & $334(27.9)$ & & $23(44.2)$ & $12(23.1)$ & \\
\hline \multicolumn{8}{|c|}{ Stoma construction at primary surgery } \\
\hline No stoma & 1008 & $61(80.3)$ & $947(79.2)$ & 0.87 & $45(86.5)$ & $41(78.8)$ & 0.29 \\
\hline Deviating stoma & 200 & $11(14.5)$ & $189(15.8)$ & & $6(11.5)$ & $11(21.2)$ & \\
\hline Missing & 64 & $4(5.3)$ & $60(5.0)$ & & $1(1.9)$ & - & \\
\hline
\end{tabular}


was significant longer for AL patients (14 days, IQR 6-23), compared to non-leak patients (5 days, IQR 3-8; $p<0.01$ ).

\section{Assessment of CT-scans for mesenteric occlusive disease}

In total, the CT-scans of $52 \mathrm{AL}$ patients and 52 matched non-leak patients were reviewed (Table 2). Sixty-seven patients $(64 \%)$ had no atherosclerotic lesions of the IMA. Thirty-four of these patients (65\% of 52 AL patients) developed AL and 33 (64\%) patients did not develop AL. Fifteen patients (14\%) had a stenosis $<50 \%$ of the IMA, including two AL patients (4\%) and thirteen non-leak patients (25\%). In ten patients (10\%) a stenosis $\geq 50 \%-70 \%$ of the IMA was found, with five patients (10\%) in both the $\mathrm{AL}$ and non-leak group. A clinically significant stenosis $(\geq 70-100 \%)$ of the IMA was found in twelve patients $(12 \%)$, eleven of these patients $(21 \%)$ developed AL and one patient $(2 \%)$ did not develop AL $(p=0.01)$. The presence of mesenteric occlusive disease of the IMA was statistically significant associated with $\mathrm{AL}(p=0.01)$. Six out of eleven of the AL patients with a clinically significant stenosis of the IMA were diagnosed with a left-sided colon tumor and five had a rectum tumor. In none of these patients a high-tie technique was performed. Four out of eleven AL patients with mesenteric occlusive disease were smokers or had a history of smoking, without statistically significant differences in smoking status between AL patients with mesenteric occlusive disease and $\mathrm{AL}$ patients without mesenteric occlusive disease $(p=0.67)$.
Ninety-one patients $(88 \%)$ had no atherosclerotic lesions of the SMA. AL was diagnosed in 44 patients $(85 \%)$ and 47 patients $(90 \%)$ did not develop AL. In ten patients $(10 \%)$ a stenosis $<50 \%$ of the SMA was found, of which six patients (12\%) developed AL and four patients $(8 \%)$ did not develop AL. One patient had a stenosis $\geq 50 \%-70 \%$ of the SMA, whom developed AL. A clinically significant stenosis $\geq 70 \%-100 \%$ was found in two patients, with one patient in each of the groups. There were no statistically significant differences found in the presence of mesenteric occlusive disease of the SMA between AL patients and non-leak patients $(p=0.68)$. Seventy-four patients (71\%) showed no atherosclerotic lesions of the CA on CT-scan, of which 39 patients (75\%) developed AL and 35 patients $(67 \%)$ did not develop AL. Twenty-six patients (25\%) had a stenosis $<50 \%$ of the CA. AL developed in eleven of these patients (21\%) and fifteen patients (29\%) did not develop AL. Two patients $(2 \%)$ had a stenosis of $\geq 50 \%-70 \%$ of the CA, with one patient (2\%) in both groups. A clinically significant stenosis $(\geq 70-100 \%)$ of the CA was found in two patients that were equally divided over the groups. No statistically significant differences were found in the presence of mesenteric occlusive disease of the CA between AL patients and non-leak patients $(p=0.84)$. The presence of a collateral network between the SMA and IMA could only be observed in a minority of the patients due to insufficient quality of the CT-scans. Collateral arteries were found in fourteen AL patients (26\%) and in four matched non-leak patients (7\%). None of the patients had a pathological Riolan artery.

Table 2 Evaluation of mesenteric atherosclerotic lesions of the celiac artery, superior mesenteric artery and inferior mesenteric artery on preoperative abdominal CT-scan

\begin{tabular}{|c|c|c|c|c|}
\hline & Total patients & $\begin{array}{l}\text { Anastomotic } \\
\text { leakage patients }\end{array}$ & $\begin{array}{l}\text { Matched "no anastomotic } \\
\text { leak" patients }\end{array}$ & $\begin{array}{l}p \text {-value } A L \text { vs. } \\
\text { matched no } A L\end{array}$ \\
\hline & $N=104$ & $N=52$ & $N=52$ & \\
\hline \multicolumn{5}{|l|}{ Celiac artery } \\
\hline No stenosis & $74(71.2)$ & $39(75.0)$ & $35(67.3)$ & \multirow[t]{4}{*}{0.84} \\
\hline Stenosis $<50 \%$ & $26(25.0)$ & $11(21.2)$ & $15(28.8)$ & \\
\hline Stenosis $\geq 50 \%-70 \%$ & $2(1.9)$ & $1(1.9)$ & $1(1.9)$ & \\
\hline Clinical significant stenosis $(\geq 70-100 \%$ stenosis $)$ & $2(1.9)$ & $1(1.9)$ & $1(1.9)$ & \\
\hline \multicolumn{5}{|l|}{ Superior mesenteric artery } \\
\hline No stenosis & $91(87.5)$ & $44(84.6)$ & $47(90.4)$ & \multirow[t]{4}{*}{0.68} \\
\hline Stenosis $<50 \%$ & $10(9.6)$ & $6(11.5)$ & $4(7.7)$ & \\
\hline Stenosis $\geq 50 \%-70 \%$ & $1(1.0)$ & $1(1.9)$ & $0(0.0)$ & \\
\hline Clinical significant stenosis $(\geq 70-100 \%$ stenosis $)$ & $2(1.9)$ & $1(1.9)$ & $1(1.9)$ & \\
\hline \multicolumn{5}{|l|}{ Inferior mesenteric artery } \\
\hline No stenosis & $67(64.4)$ & $34(65.4)$ & $33(63.5)$ & \multirow[t]{4}{*}{0.01} \\
\hline Stenosis $<50 \%$ & $15(14.4)$ & $2(3.8)$ & $13(25.0)$ & \\
\hline Stenosis $\geq 50 \%-70 \%$ & $10(9.6)$ & $5(9.6)$ & $5(9.6)$ & \\
\hline Clinical significant stenosis $(\geq 70-100 \%$ stenosis $)$ & $12(11.5)$ & $11(21.2)$ & $1(1.9)$ & \\
\hline
\end{tabular}




\section{Discussion}

Preoperative prediction of the risk for AL is crucial, since mortality and morbidity rates remain high and the pathophysiology of AL is unknown. In this retrospective cohort study of 1273 patients with left-sided colon or rectal cancer, 76 patients were diagnosed with AL. We showed that the presence of mesenteric occlusive disease of the IMA on preoperative CT-scan was significantly associated with $\mathrm{AL}$ in left-sided colon or rectal cancer surgery. No association between the presence of mesenteric occlusive disease of the SMA and CA and AL was found. Univariable analysis revealed LAR and stage I-III disease to be associated with an increased risk for AL. No other differences in baseline patient characteristics were found between $\mathrm{AL}$ and non-leak patients. AL patients had statistically significant worse postoperative outcomes including a higher ICU admission rate, a higher 90-day readmission rate and a prolonged length of hospital stay.

There is little available evidence on the association of atherosclerotic lesions of mesenteric arteries on anastomotic healing published yet. Until now, there has been only one study analyzing the association of the presence of atherosclerotic lesions of the mesenteric arteries on preoperative CT-scan with AL. Kornmann et al. analyzed 96 patients undergoing left-sided colon or rectal resection and concluded in contrast to our results, that AL was not associated with the presence of atherosclerotic lesions of the IMA [16]. Also, stenoses $\geq 50 \%$ of the IMA were found in $21 \%$ of the non-leak patients, which is about two times higher compared to our study. These results may be explained by the fact that they did not compare AL patients to a matched non-leak group and by the lack of sufficient power since only fourteen AL patients were analyzed.

We demonstrated that clinically significant stenosis of the IMA is statistically significant more prevalent on the preoperative abdominal CT-scan of AL patients. This finding can be explained by mesenteric occlusive disease limiting the blood flow of the IMA, creating a "functional high-tie" and as a result, limiting anastomotic perfusion and contributing to the development of disrupted healing $[8,17]$.

In contrast to the limited available evidence on the association of mesenteric occlusive disease with AL, atherosclerotic calcification of larger systemic arteries including the aorta and iliac arteries in relation to AL has been of more interest. Most of these studies quantified atherosclerotic calcification with the calcium score, that is calculated by the total sum of the atherosclerotic load in the analyzed arterial trajectory. Histopathological studies demonstrated that the calcium area is correlated with the atherosclerotic plaque area [18]. Komen et al. analyzed 122 patients (including eleven ALs) undergoing colorectal surgery and concluded that patients with higher calcium scores in both common iliac arteries and the left internal iliac artery were associated with an increased AL risk [14]. Pochhammer et al. found similar results when analyzing 139 patients (including fourteen ALs) who underwent colorectal resection with rectal anastomosis [19]. It is difficult to explain these results anatomically, since the left internal iliac artery and its branches only supply the inferior part of the rectum, and most of the patients in these studies had an anastomosis located in the upper rectum or more proximal. However, in a case-control study of Boersema et al. 145 patients (including $30 \mathrm{ALs}$ ) undergoing colorectal resection with left-sided anastomosis, the calcium score did not correlate with the development of AL [20]. Therefore, evidence for the aorto-iliac calcium score as preoperative predictor for AL is conflicting.

To our best knowledge, this is the first study evaluating the association of mesenteric occlusive disease with $\mathrm{AL}$ in a large population undergoing left-sided or rectal cancer surgery. Strengths of this study are the significant number of patients with AL that was included and its case-control design. By comparing AL patients to matched non-leak patients from the same cohort, we reduced selection bias and confounding of potential vascular risk factors (e.g. age, BMI, cardiovascular comorbidity). However, data was analyzed, respectively, and we could only evaluate the CT-scans of the patients in whom a CT-scan was performed for preoperative cancer staging. These CT-scans were not primarily performed to assess atherosclerotic lesions, and therefore, some CT-scans were not of sufficient quality to evaluate the mesenteric vascularization. We also could not draw conclusions on the role of the collateral mesenteric circulation due to insufficient quality of the CT-scan. Due to lack of data on smoking status of non-leak patients we did not study the association between smoking status and the presence of mesenteric occlusive disease in the total population. However, there was no statistically significant difference in the smoking status between AL patients with a clinically significant stenosis $(\geq 70-100 \%$ stenosis) of the IMA and AL patients without a clinically significant stenosis $(<70 \%$ stenosis) of the IMA. In addition, smoking is a risk factor for cardiovascular disease and by controlling for cardiovascular disease in the case-control design, we aimed to limit bias of lack on data on smoking status.

In conclusion, we demonstrated that the presence of a clinically significant stenosis of the IMA on preoperative abdominal CT-scan is associated with AL after left-sided colon or rectal resection for cancer. Further prospective studies with additional $\mathrm{CT}$ imaging are needed to validate our results and to study the role of collateral vascularization. Preoperative identification of patients at risk of AL with 
CT-contrast enhanced imaging as part of routine care could be of great value for the current colorectal surgery practice. Until future studies are awaited, additional preoperative imaging such as CT-angiography seems to be indicated in patients with a high risk on AL. When mesenteric occlusive disease of the IMA is diagnosed in these patients, surgeons could perhaps consider preoperative percutaneous transluminal angioplasty (PTA) to improve inadequate anastomotic perfusion to lower the risk of AL.

Supplementary Information The online version contains supplementary material available at https://doi.org/10.1007/s00384-021-04089-0.

\section{Declarations}

Conflict of interest The authors declare no competing interests.

Open Access This article is licensed under a Creative Commons Attribution 4.0 International License, which permits use, sharing, adaptation, distribution and reproduction in any medium or format, as long as you give appropriate credit to the original author(s) and the source, provide a link to the Creative Commons licence, and indicate if changes were made. The images or other third party material in this article are included in the article's Creative Commons licence, unless indicated otherwise in a credit line to the material. If material is not included in the article's Creative Commons licence and your intended use is not permitted by statutory regulation or exceeds the permitted use, you will need to obtain permission directly from the copyright holder. To view a copy of this licence, visit http://creativecommons.org/licenses/by/4.0/.

\section{References}

1. Park JS, Huh JW, Park YA, Cho YB, Yun SH, Kim HC et al (2016) Risk factors of anastomotic leakage and long-term survival after colorectal surgery. Medicine (Baltimore) 95(8):e2890

2. Bakker IS, Grossmann I, Henneman D, Havenga K, Wiggers $\mathrm{T}$ (2014) Risk factors for anastomotic leakage and leak-related mortality after colonic cancer surgery in a nationwide audit. Br J Surg 101(4):424-32; discussion 32

3. La Regina D, Di Giuseppe M, Lucchelli M, Saporito A, Boni L, Efthymiou C et al (2019) Financial Impact of anastomotic leakage in colorectal surgery. J Gastrointest Surg 23(3):580-586

4. Thomas MS, Margolin DA (2016) Management of colorectal anastomotic leak. Clin Colon Rectal Surg 29(2):138-144

5. Poelemeijer YQM, Lijftogt N, Detering R, Fiocco M, Tollenaar $R$, Wouters M (2018) Obesity as a determinant of perioperative and postoperative outcome in patients following colorectal cancer surgery: a population-based study (2009-2016). Eur J Surg Oncol 44(12):1849-1857
6. Kruschewski M, Rieger H, Pohlen U, Hotz HG, Buhr HJ (2007) Risk factors for clinical anastomotic leakage and postoperative mortality in elective surgery for rectal cancer. Int J Colorectal Dis 22(8):919-927

7. Vignali A, Gianotti L, Braga M, Radaelli G, Malvezzi L, Di Carlo V (2000) Altered microperfusion at the rectal stump is predictive for rectal anastomotic leak. Dis Colon Rectum 43(1):76-82

8. Komen N, Slieker J, de Kort P, de Wilt JHW, van der Harst E, Coene P-P et al (2011) High tie versus low tie in rectal surgery: comparison of anastomotic perfusion. Int J Colorectal Dis 26(8):1075-1078

9. Kawada K, Hasegawa S, Wada T, Takahashi R, Hisamori S, Hida $\mathrm{K}$ et al (2017) Evaluation of intestinal perfusion by ICG fluorescence imaging in laparoscopic colorectal surgery with DST anastomosis. Surg Endosc 31(3):1061-1069

10. Foster ME, Brennan SS, Morgan A, Leaper DJ (1985) Colonic ischaemia and anastomotic healing. Eur Surg Res 17(3):133-139

11. Greenwald DA, Brandt LJ, Reinus JF (2001) Ischemic bowel disease in the elderly. Gastroenterol Clin North Am 30(2):445-473

12. Tong L, Xie D, Song X, Wu X, Wen S, Liu A (2020) Is abdominal vascular calcification score valuable in predicting the occurrence of colorectal anastomotic leakage? A meta-analysis. Int J Colorectal Dis 35(4):641-653

13. Eveno C, Latrasse V, Gayat É, Lo Dico R, Dohan A, Pocard M (2016) Colorectal anastomotic leakage can be predicted by abdominal aortic calcification on preoperative CT scans: a pilot study. J Visc Surg 153(4):253-257

14. Komen N, Klitsie P, Dijk JW, Slieker J, Hermans J, Havenga K et al (2011) Calcium score: a new risk factor for colorectal anastomotic leakage. Am J Surg 201(6):759-765

15. van Petersen AS, Kolkman JJ, Meerwaldt R, Huisman AB, van der Palen J, Zeebregts CJ et al (2014) Mesenteric stenosis, collaterals, and compensatory blood flow. J Vasc Surg 60(1):111-9.e2

16. Kornmann VN, van Werkum MH, Bollen TL, van Ramshorst B, Boerma D (2014) Compromised visceral circulation does not affect the outcome of colorectal surgery. Surg Today 44(7):1220-1226

17. Lange MM, Buunen M, van de Velde CJ, Lange JF (2008) Level of arterial ligation in rectal cancer surgery: low tie preferred over high tie. A review Dis Colon Rectum 51(7):1139-1145

18. Rumberger John A, Simons DB, Fitzpatrick Lorraine A, Sheedy Patrick F, Schwartz RS (1995) Coronary artery calcium area by electron-beam computed tomography and coronary atherosclerotic plaque area. Circulation 92(8):2157-2162

19. Pochhammer J, Tröster F, Blumenstock G, Closset J, Lang S, Weller MP et al (2018) Calcification of the iliac arteries: a marker for leakage risk in rectal anastomosis-a blinded clinical trial. Int J Colorectal Dis 33(2):163-170

20. Boersema GSA, Vakalopoulos KA, Kock MCJM, van Ooijen PMA, Havenga K, Kleinrensink GJ et al (2016) Is aortoiliac calcification linked to colorectal anastomotic leakage? A case-control study. Int J Surg 25:123-127

Publisher's Note Springer Nature remains neutral with regard to jurisdictional claims in published maps and institutional affiliations. 